\title{
Research on Hospitality Management Based on the Development of Tourism Economy
}

\author{
Xuhong Jia \\ Qingdao Huanghai University, Qingdao, 266427, China
}

Keywords: Tourism economy, Hotel management, Necessity, Issue, Countermeasure

\begin{abstract}
With the development of economy and the continuous adjustment of industrial structure, tourism economy is becoming more and more important in the national economy. Hospitality management, which is closely related with tourism economy, will need to improve their management level if they want to seize this opportunity so that they can facilitate tourism, and push forward by the tourism. This paper mainly analyzes three aspects of the hotel management: significance of hotel management in the context of the development of tourism economy, existing issues and its resolving measures.
\end{abstract}

\section{Introduction}

Along with the social progress and development, people's living standards have been improved, after meeting food and clothing needs, people start to pay more attention to the spiritual life, which promoted the change of the industrial structure. Changes in consumption lead to the adjustment of our economy structure and boosted the development of the third industry. Tourist economy and hospitality management, as important factors in third industry, have experienced enormous growth. It's quite necessary to further study hotel management in line with tourist economy to gain long term development.

\section{The significance of hotel management research based on the development of tourism economy}

\section{To help meet the needs of visitors}

Economic and social development provides more ways to travel such as self- driving tour, riding, and creative tour and so on. Although people have more convenient travel tools, but for some long haul tourists, the equipment poses certain security risks. For example, people on self- driving tour will prepare lots of items, but if these items are placed in the cart, they may got stolen or damaged. Therefore, they need a hotel to provide more secured sites, thus to ensure property safety. In addition, for some ecological tour visitors, their agenda usually last more than a day, if they do not preserve picked fruit properly, will become stale or even rotten, while hotel can effectively solve this problem [1].

\section{To meet the physiological needs of tourists}

Visitors, no matter what kind tour, will be tired at the end of the day, the body needs to rest. Hotel's main business is to provide visitors with a comfortable place, so as to help visitors solve the problem. In addition, the hotel is also equipped with TV, air conditioning, bath and other equipment, for visitors to eliminate fatigue, and be fresh for tomorrow's agenda. Besides, hotels have better environment, brings people comfortableness to keep visitors in a good mood.

\section{To meet the cultural needs of tourists}

Travel is closely related to culture, hotel can provide supplementary service to tourists, which means clear the sense of strangeness, answer questions, doubts for the visitors before they actually go there. In addition, some hotels put books, magazines in the room for spiritual needs, such as the 
Hanting Hotels place all kinds of books in each room, which can not only provide entertainment for visitors, but also effectively improve the cultural connotation of the hotel [2].

\section{Major issues of hotel management under the background of tourism economy}

\section{Hotel service facilities to be improved}

Some of the existing high-end hotels have some issues in their service equipment, which is: first, there is certain gap compared with counterparts in developed countries, intelligent level is low, service is still majorly dependent on manpower; second, the equipment cannot be updated timely. Some of the hotel's equipment is aging seriously, and some equipment even cannot maintain normal operation; third, technical content of service equipment is low. Some hotels purchase mismatching equipment to cut cost, which brings down the consumption feelings of visitors.

\section{Hotel management system to be improved}

Hotel management system is the main basis for the hotel staff to carry out work, but some hotels failed to adjust the hotel management according to the development of the market economy which affected the development of the hotel. First, the development of market economy has great impact on the hotel management which requires hotel to define job responsibilities and scope of work clearly, divide management more clear and more specific, but some hotels cannot see the situation; they still use the traditional work model which affects the management level; second, corporate culture. Corporate culture can affect the enthusiasm of the staff, and their performance. But some hotels still regard enterprise revenue as the core of management, which affected the stuff's enthusiasm to some extent [3].

\section{Hotel staff quality to be improved}

Hospitality management has certain scale in our country; therefore it requires competent professional talents to do hotel management, so as to improve the hotel management level. Our current hotel management needs to improve in two aspects: on one hand, the quality OF hotel management personnel is not high. A large number of current hotel management personnel in our country is from other industries, so their professional knowledge and skills is weak; on the other hand, in hiring process, hotel does not have strict selection policy, pulling strings to get jobs is common, resulting in the loss of professionals, which has a great influence on the improvement of hotel management.

\section{The measures to solve the problem of hotel management under the background of tourism economy}

\section{To establish a sound hotel management system}

Hotel management system is the basis of hotel management, hotel leaders need to prepare management system that is conducive to long term development according to the needs of the times and the development of the hotel. So, hotels need to complete management system as follows:

Post responsibility system

In hotel management system, first of all, define post responsibility and work scope at all levels and all posts clearly, so as to ensure the hotel management personnel to carry out their duties in the process of work, to promote orderly and effective work; secondly, define consequence clearly if error arises from their post to urge them take work seriously, improve efficiency and prevent errors; finally, strictly implement the system of post responsibility. Hotel needs to earnestly implement the relevant requirements of the system of job responsibility in the process of management, thereby enhancing the employee attention on the job, enhance their sense of responsibility, and promote employees to work conscientiously and strictly.

Talent selection system 
For selection of personnel, hotel needs to develop a strict selection system; the following aspects need to be considered in the formulation of the selection system: first, to expand the scope of choice, if hotels want to get good talent, hotels need to expand the scope. to expand the selection of ways, hotels need to strengthen the use of modern technology such as network, media, etc.; second, to develop the examination and vetting process. Hotels can set up solid and mandatory condition to screen, then select through writing test, interview, internship and other ways, conduct a comprehensive investigation on their professional knowledge, professional skills and personal ability, so as to ensure the selection of qualified personnel in line with the hotel development [4]. In addition, hotels need to pay attention to fairness of the selection in this process; this can be achieved through public interview and other ways to ensure the objectivity of personnel selection.

\section{Supervision and management system}

A sound regulatory system should be able to regulate the behavior of the regulators, and ensure orderly and standard operation. Therefore, the hotel needs to strengthen two aspects of supervision when developing regulatory system. On one hand, strengthen internal supervision. The hotel needs to develop special regulatory authorities, regulatory authorities are directly under the leadership of the hotel leaders, and they supervise other departments and report back to leaders. On the other hand, strengthen external supervision. Hotels can strengthen supervision among stuff, and present management result to public so that management can be supervised by staff in the hotel. This will not only improve the level of hotel management, but also enhance the enthusiasm for hotel staff to participate in the hotel management, and enhance the cohesion of the hotel, and promote the development of enterprises.

The establishment of excellent corporate culture

Excellent corporate culture can create a good working atmosphere, increase the enthusiasm of employees, promote the hotel service level. For that, hotel can cultivate new corporate culture based on the current situation and existing culture, and then through meeting, distribution of work manual and other approaches to advertise corporate cultures such as management philosophy and other contents so that employees can clearly understand the corporate culture, to have deep understanding on corporate culture, to resonate with corporate culture to promote their work positively, enhance the unity and cohesion, form good work atmosphere, to improve the overall of hotel management [5].

Details

\section{Improve service equipment}

\section{Sound hardware facilities}

The hotel's hardware facilities will impact direct vision to visitors, it is the most intuitive and direct embodiment of the hotel's comprehensive competence. So it is very necessary to improve the hotel's hardware facilities. Hotels can improve the following aspects: first, ensure the comfortableness of the equipment. Visitors will want to rest comfortably after travel, so ensuring the comfortableness is very important. Therefore, when decorating the hotel, make it a priority; second, build the hotel with theme. Theme for a hotel should be selected in combination with actual situations. For example, for hotels surrounded by scenic spots, try to choose a warm and comfortable theme, so that visitors can feel at home and get physical and mental relaxation.

Perfect supporting facilities

Hotels with different consumer groups will need different supporting facilities. For example, if a hotel's consumer groups are mainly tourists, then the hotel needs to develop a variety of different needs of services, such as tour guides, travel line services, ticketing services, so as to provide more convenient services to retain customers. If the hotel wants to provide these supporting facilities, the hotel needs to have complete communication system to ensure smoothness of information and operation of each sequence.

\section{Improve the quality of hotel management}

The quality of the hotel management has an important impact on the management level of the hotel; the hotel can improve the quality of management personnel from the following aspects: 
First, strengthen the management personnel training. Training is the most effective measure to improve the quality of hotel management. the hotel can organize periodic hotel management training, enrich the professional skills of management, improve the quality of hotel management personnel, improve the management level, and reduce the gap with developed countries; besides, during training, hotel needs to train their computer skills so that the management can master software faster;

Second, change the concept of management personnel. with the development of society and people's cognitive level, the traditional management ideas cannot adapt to the current management, hotel management personnel need to change the current management philosophy, adhere to people-oriented service concept, to provide more personalized service for hotel guests, so that visitors can experience the feeling of home after travel, so that employees can be motivated;

Third, the establishment of a comprehensive incentive mechanism, incentive mechanism can effectively stimulate staff's working efficiency, promote the wine service. To this end, the hotel can formulate hotel's own incentive mechanism according to its own actual situation, give material and spiritual encouragement for excellent performance, and punish employees appropriately who can't take a correct attitude towards work to motivate staff, promote the level of the hotel service management, let visitors feel at home after the trip.

Fourth, to enhance language competence, with the development of economic integration, China's beautiful scenery will attract more and more foreign visitors to China. Therefore, the hotel management staff also needs to constantly improve their language knowledge, learning English, so as to be able to communicate with foreign tourists to provide quality services for foreign tourists.

\section{Conclusion}

To sum up, development of tourism has brought opportunities and challenges for hotel's development. Hotel management personnel need to seize the opportunity to meet the challenges of the hotel management, adjust and improve the management system which is not consistent with the current development of the times, improve the management system, and promote the hotel management level, promote healthy and long-term development of the hotel.

\section{References}

[1] He Yuanqing, Wang Shuxin, Wang Xueding etc. Regional Development Characteristics and Influencing Factors of Tourism Economy in China. Commercial Economy and Management, 2011 (4): 89-96.

[2] Cai Chenghao, Zhang Zhonglan. Study on the Problems and Countermeasures of the Development of Modern Tourism Industry. Contemporary Travel (a), 2012 (10): 28-29.

[3] Zhai Yuntao. The Present Situation and Improvement of Service Ability of Economic Hotel. Modern Enterprise Culture, 2014 (6): 75-76.

[4] Liu Qingqing. Hotel Management Exploration under the Situation of Tourism Economy. Journal of Yangtze University: Social Science Edition, 2012,35 (10): 70-71.

[5] Lian Jianhua. Village Hotel Chain Management Mode Research under the Background of the Ecological Tourism -- Pandas Post House in Dujiangyan as Example. Sichuan Provincial Committee of the Communist Party of China Provincial Organs of the Party School Journal, 2013 (4): 101-105. 